\title{
Modeling sorption isotherms and isosteric heat of sorption of roasted coffee beans
}

\author{
Collazos-Escobar, G.A. ${ }^{a^{*}}$; Gutiérrez-Guzmán, N.a ; Váquiro-Herrera, H.A. ${ }^{\text {; }}$; Cortes- \\ Macias, E.T. ${ }^{a}$ \\ ${ }^{a}$ Facultad de Ingeniería. Centro Surcolombiano de Investigación en Café CESURCAFÉ. Universidad \\ Surcolombiana. Neiva-Huila-Colombia.

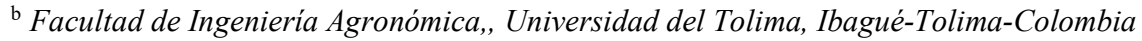 \\ *E-mail of the corresponding author: gentlcollazosescobar09@gmail.com
}

\begin{abstract}
The aim of this work was determine the sorption isotherms in roasted beans of specialty coffee at temperatures of 25,30 and $40{ }^{\circ} \mathrm{C}$ and water activities between 0.1 and 0.8 using the dynamic dew point method. The experimental sorption data were modeled using 12 different equations to represent the dependence of equilibrium moisture content with $a_{w}$ and temperature. The net isosteric heat of sorption was determined from the experimental sorption data using the Clausius-Clapeyron equation. The Weibull model satisfactorily modeled the effect of the temperature on the hygroscopic equilibrium in roasted coffee beans $\left(R^{2}{ }_{\text {adj }}=0.902\right.$ and $R M S E=0.005 \mathrm{~kg} \cdot \mathrm{kg}^{-1}$ d.b. $)$. The net isosteric heat of sorption increase with increased moisture content.
\end{abstract}

Keywords: water activity; sorption properties; equilibrium moisture content; hygroscopicity. 


\section{Introduction}

Coffee beans are a highly hygroscopic matrix and could readily take up moisture when exposed to the environment during storage [8], this condition may affect the coffee bean freshness. For proper handling of roasted coffee beans, it is necessary to know, among other properties, the water sorption isotherms, which describe the relationship between the equilibrium moisture content and the water activity at constant temperature and pressure [2]. There are many sorption models proposed in literature to represent the water sorption in foods [16], some models are empirical or semi-empirical equations. Due to the complex in the food matrices, there are not a unique model to describe entirely of the agri-food products [3]; therefore, is necessary to validate from experimental data the best model for both the material and the air conditions.

The objective of this work was to determine and model the moisture isotherms of roasted coffee beans at temperatures of 25,30 and $40{ }^{\circ} \mathrm{C}$ and water activities between 0.1 and 0.8 using the dynamic dew point method.

\section{Materials and Methods}

\subsection{Coffee samples}

Nine samples of wet processed coffee (Coffea arabica L.) from Huila region (Colombia) were sensory analyzed to SCAA (Specialty Coffee Association of America) methodology in the South Colombian Coffee Research Center (CESURCAFÉ) by four experts panelists [12]. The coffee beans were roasted in a laboratory equipment (TC-150R,Quantik, Colombia).

\subsection{Experimental determination of the sorption isotherms}

Sorption isotherms were determined at water activities between 0.1 and 0.8 and temperatures of 25,30 and $40^{\circ} \mathrm{C}$ by the dynamic dew point method (DDI). The measurements were carried out in a Vapor Sorption Analizer (VSA Aqualab Decagon Device, Inc. Pullman, WA) at water-activity intervals of 0.01 and 0.05 for adsorption and desorption, respectively, and a flow rate of $100 \mathrm{ml} \cdot \mathrm{min}^{-1}$.

\subsection{Modeling sorption isotherms}

The sorption isotherms of roasted coffee beans were represented mathematically using the 12 models shown in Table 1, where $X_{e}$ is the equilibrium moisture content $\left(\mathrm{kg} \cdot \mathrm{kg}^{-1}\right.$, dry basis), $a_{w}$ is the water activity, $K, C, C_{0}$ and $K_{0}$ are GAB model parameters, $H_{\mathrm{m}}$ is the monolayer sorption heat $\left(\mathrm{kJ} \cdot \mathrm{mol}^{-1}\right), H_{\mathrm{n}}$ is the multilayer sorption heat $\left(\mathrm{kJ} \cdot \mathrm{mol}^{-1}\right), \lambda$ is the evaporation enthalpy of water $\left(\mathrm{kJ} \cdot \mathrm{mol}^{-1}\right), T$ is the absolute temperature $(\mathrm{K}), R$ is the universal gas constant $\left(\mathrm{kJ} \cdot \mathrm{mol}^{-1} \cdot \mathrm{K}^{-1}\right)$ and $b_{i}$ are empirical model parameters. 
Table 1. Mathematical model to define roasted coffee beans isotherms

\begin{tabular}{|c|c|c|c|}
\hline Model & Reference & Mathematical expression & Equation \\
\hline GAB & {$[6,10]$} & $\begin{array}{c}X_{e}=\frac{X_{m} C K a_{w}}{\left[\left(1-K a_{w}\right)\left(1-K a_{w}+C K a_{w}\right)\right]} \\
C=C_{o} \exp \left(\frac{H_{m}-H_{n}}{R T}\right) \\
K=K_{0} \exp \left(\frac{\lambda-H_{n}}{R T}\right)\end{array}$ & $\begin{array}{l}\text { (2) } \\
(3)\end{array}$ \\
\hline Oswin & {$[1]$} & $X_{e}=b_{1}\left(\frac{a_{w}}{1-a_{w}}\right)^{b_{2}}$ & (4) \\
\hline Smith & {$[13]$} & $X_{e}=b_{1}+b_{2} \ln \left(1-a_{w}\right)$ & (5) \\
\hline $\begin{array}{l}\text { Chung- } \\
\text { Pfost }\end{array}$ & {$[11]$} & $X_{e}=b_{1}+b_{2} \ln \left(-\ln a_{w}\right)$ & (6) \\
\hline Kunh & {$[15]$} & $X_{e}=\left(\frac{b_{1}}{\ln a_{w}}\right)+b_{2}$ & (7) \\
\hline Caurie & {$[9]$} & $X_{e}=\exp \left(b_{1}+b_{2} a_{w}\right)$ & (8) \\
\hline $\begin{array}{l}\text { Iglesias and } \\
\text { Chirife }\end{array}$ & {$[5]$} & $X_{e}=b_{1}+b_{2}\left(\frac{a_{w}}{1-a_{w}}\right)$ & (9) \\
\hline $\begin{array}{l}\text { White and } \\
\text { Eiring }\end{array}$ & {$[15]$} & $X_{e}=\frac{1}{\left(b_{1}+b_{2} a_{w}\right)}$ & $(10)$ \\
\hline Peleg & {$[14]$} & $X_{e}=b_{0} a_{w}^{b_{1}}+b_{2} a_{w}^{b_{3}}$ & (11) \\
\hline DLP & {$[14]$} & $\begin{array}{c}X_{e}=b_{0}+b_{1} x+b_{2} x^{2}+b_{3} x^{3} \\
x=\ln \left(-\ln a_{w}\right)\end{array}$ & (12) \\
\hline Polynomial & {$[11]$} & $X_{e}=b_{0}+b_{1} a_{w}+b_{2} a_{w}^{2}+b_{3} a_{w}^{3}$ & (13) \\
\hline Weibull & {$[17]$} & $X_{e}=b_{1}+\exp ^{b_{2}\left(1-a_{w}\right)^{b_{3}}}$ & (14) \\
\hline
\end{tabular}

*It has been considered that the parameters of the empirical equations have a linear dependence with the temperature $\left(b_{i} T_{a b s}+b_{i .1}\right)$. 


\subsubsection{Parameter estimation and statistical analysis}

The tool Curve Fitting of Matlab® R2017b (The MathWorks Inc., Natick, MA, USA) was used to identify the model parameters and calculate the $95 \%$ confidence intervals of parameters. The adjusted determination coefficient $\left(R^{2}\right.$ adj $)$ and the root mean square error (RMSE) were used as goodness-of-fit statistics.

\subsection{Determination of the net isosteric heat of sorption}

Sorption heats were calculated through the direct use of moisture sorption isotherms by applying the Clausius-Clapeyron equation (15). Estimations of net isosteric heat of sorption have been found in literature integrating Equation (15) between two temperatures (Eq.(16)). It is reported in literature that Riedel equation (17) adequately describes the influence of temperature on water activity. By combining Equations (16) and (17), another expression to estimate net isosteric heat of sorption may be considered (Eq. (18)) [7].

$$
\begin{gathered}
q_{s n}=-R\left[\frac{\partial\left(\ln a_{w}\right)}{\partial\left(\frac{1}{T}\right)}\right] x \\
q_{s n}=R\left[\frac{T_{1} T_{2}}{T_{2}-T_{1}} \ln \frac{a_{w_{2}}}{a_{w_{1}}}\right] \\
\ln \left(\frac{a_{w_{2}}}{a_{w_{1}}}\right)=A_{r} \exp \left(-B_{t} W\right)\left(\frac{1}{T_{1}}-\frac{1}{T_{2}}\right) \\
q_{s n}=C_{r} \exp \left(-B_{r} W\right)
\end{gathered}
$$

When $A_{r}, B_{r}$ are constants of the riedel equation and $C_{r}$ being $A r \cdot R$.

\section{Results and Discussion}

The Table 2 presents the four mathematical models with the best fit of the experimental data, considering the effect of temperature; the Weibull model could be considered the which best represent experimental data, since reached high value of the $R^{2}{ }_{\text {ajs }}$ coefficient 0.902 and $R M S E$ lower than $0.01 \mathrm{~kg} \cdot \mathrm{kg}^{-1} \mathrm{~d} . \mathrm{b}$; the others eight mathematical models (Smith, Chung pfost, White and Eiring, Caurie, Iglesias and Chirife, Kunh, Oswin y Peleg) they resulted with values of the $R_{\text {ajs }}^{2}$ coefficient below 0.8 and $R M S E$ higher than $0.1 \mathrm{~kg} \cdot \mathrm{kg}^{-1} \mathrm{~d} . \mathrm{b}$. 
Table 2. Estimated model parameters and statist

\begin{tabular}{|c|c|c|c|c|}
\hline Models & Parameters & $\begin{array}{c}\text { Confidence Intervals } \\
95 \%\end{array}$ & $R^{2}$ adj & RMSE \\
\hline \multirow{7}{*}{ Polynomial } & $b_{3}=0.677$ & {$[0.596,0.757]$} & \multirow{7}{*}{0.881} & \multirow{7}{*}{0.006} \\
\hline & $b_{2.1}=7.201 \times 10^{-3} \mathrm{~K}^{-1}$ & {$\left[4.972 \times 10^{-3}, 9.43 \times 10^{-3}\right]$} & & \\
\hline & $b_{2}=-0.975$ & {$[-1.11,-0.84]$} & & \\
\hline & $b_{1.1}=-4.753 \times 10^{-3} \mathrm{~K}^{-1}$ & {$\left[-6.883 \times 10^{-3},-2.622 \times 10^{-3}\right]$} & & \\
\hline & $b_{1}=0.396$ & {$[0.313,0.479]$} & & \\
\hline & $b_{0.1}=9.488 \times 10^{-4} \mathrm{~K}^{-1}$ & {$\left[4.761 \times 10^{-4}, 1.421 \times 10^{-3}\right]$} & & \\
\hline & $b_{0}=-0.028$ & {$[-0.044,-0.012]$} & & \\
\hline \multirow{5}{*}{ DLP } & $b_{3}=-0.016$ & {$[-0.018,-0.014]$} & \multirow{5}{*}{0.895} & \multirow{5}{*}{0.005} \\
\hline & $b_{2.1}=-0.296$ & {$[-0.323,-0.269]$} & & \\
\hline & $b_{2}=9.784 \times 10^{-4} \mathrm{~K}^{-1}$ & {$\left[8.903 \times 10^{-4}, 1.066 \times 10^{-3}\right]$} & & \\
\hline & $b_{1}=5.263 \times 10^{-3}$ & {$\left[3.739 \times 10^{-3}, 6.787 \times 10^{-3}\right]$} & & \\
\hline & $b_{0}=8.071 \times 10^{-5} \mathrm{~K}^{-1}$ & {$\left[7.718 \times 10^{-5}, 8.425 \times 10^{-5}\right]$} & & \\
\hline \multirow{6}{*}{ Weibull } & $b_{3.1}=4.071$ & {$[1.731,6.41]$} & \multirow{6}{*}{0.902} & \multirow{6}{*}{0.005} \\
\hline & $b_{3}=-9.532 \times 10^{-3} \mathrm{~K}^{-1}$ & {$\left[-0.017,-1.941 \times 10^{-3}\right]$} & & \\
\hline & $b_{2.1}=-162.1$ & {$[-230.3,-93.84]$} & & \\
\hline & $b_{2}=0.47$ & {$[0.25,0.69]$} & & \\
\hline & $b_{1.1}=-0.074$ & {$[-0.106,-0.042]$} & & \\
\hline & $b_{1}=3.25 \times 10^{-4} \mathrm{~K}^{-1}$ & {$\left[2.198 \times 10^{-4}, 4.301 \times 10^{-4}\right]$} & & \\
\hline \multirow{5}{*}{ GAB } & $H_{\mathrm{m}}=3.24 \times 10^{4} \mathrm{~kJ} \cdot \mathrm{mol}^{-1}$ & {$\left[-1.849 \times 10^{5}, 2.498 \times 10^{5}\right]$} & \multirow{5}{*}{0.661} & \multirow{5}{*}{0.009} \\
\hline & $H_{\mathrm{n}}=4.50 \times 10^{4} \mathrm{~kJ} \cdot \mathrm{mol}^{-1}$ & {$\left[3.696 \times 10^{4}, 5.305 \times 10^{4}\right]$} & & \\
\hline & $C_{0}=1.983 \times 10^{4} \mathrm{~K}^{-1}$ & {$\left[-1.649 \times 10^{6}, 1.689 \times 10^{6}\right]$} & & \\
\hline & $K_{0}=1.032 \mathrm{~K}^{-1}$ & {$[-2.372,4.436]$} & & \\
\hline & $X_{\mathrm{m}}=0.019 \mathrm{~kg} \cdot \mathrm{kg}^{-1} \mathrm{~d} . \mathrm{b}$ & {$[0.015,0.022]$} & & \\
\hline
\end{tabular}

The figure 1 presents the experimentals isotherms and the values obtained with the Weibull model at 25, 30 and $40{ }^{\circ} \mathrm{C}$. The resulting isotherms are of the type III form, accord with classification of Brunauer [4]. The type III Isotherms obtained for roasted coffee beans, could be due to Maillard reactions in the roasting coffee process. 


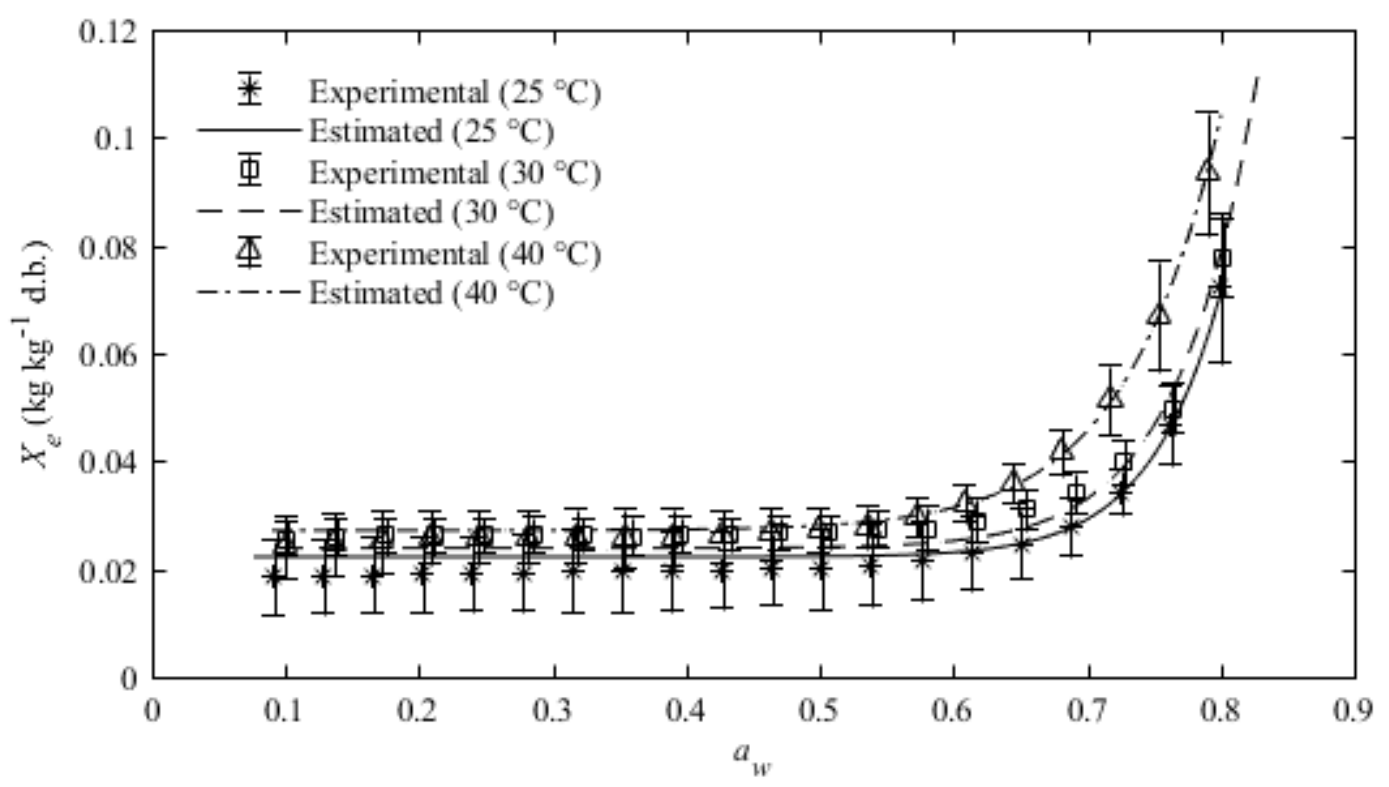

Fig 1. Experimentals Sorptiom Isotherms in roasted coffee beans at $25^{\circ} \mathrm{C}, 30^{\circ} \mathrm{C} y 40^{\circ}$

\section{Net isosteric heat of sorption $\left(q_{s n}\right)$}

The Table 3 presents the parameters and the fit coefficients for Riedel equation in the net isosteric heat of sorption estimated for roasted coffee beans. The results showed that the Riedel model not provide a good fit; besides this, in the Figure 2 showed just a similar trend but not a good fit.

Tabla 3. Estimation of the net isosteric heat of sorption with the Riedel equation

\begin{tabular}{cllll}
\hline Model & \multicolumn{1}{c}{ Parameters } & Confidence Intervals 95\% & $\boldsymbol{R}^{\mathbf{2}}$ adj & $\boldsymbol{R} \boldsymbol{R} \boldsymbol{S} \boldsymbol{E}$ \\
\hline Riedel $(\mathrm{x})=A_{r}{ }^{*} \exp (-$ & $A_{r}=-7.578 \times 10^{4}$ & {$\left[-2.261 \times 10^{-5}, 7.458 \times 10^{-4}\right]$} & 0.629 & 0.071 \\
$\left.B_{r}^{*} \mathrm{x}\right)^{*} 0.00016$ & $B_{r}=120.3$ & {$[58.03,182.5]$} & & \\
\hline
\end{tabular}




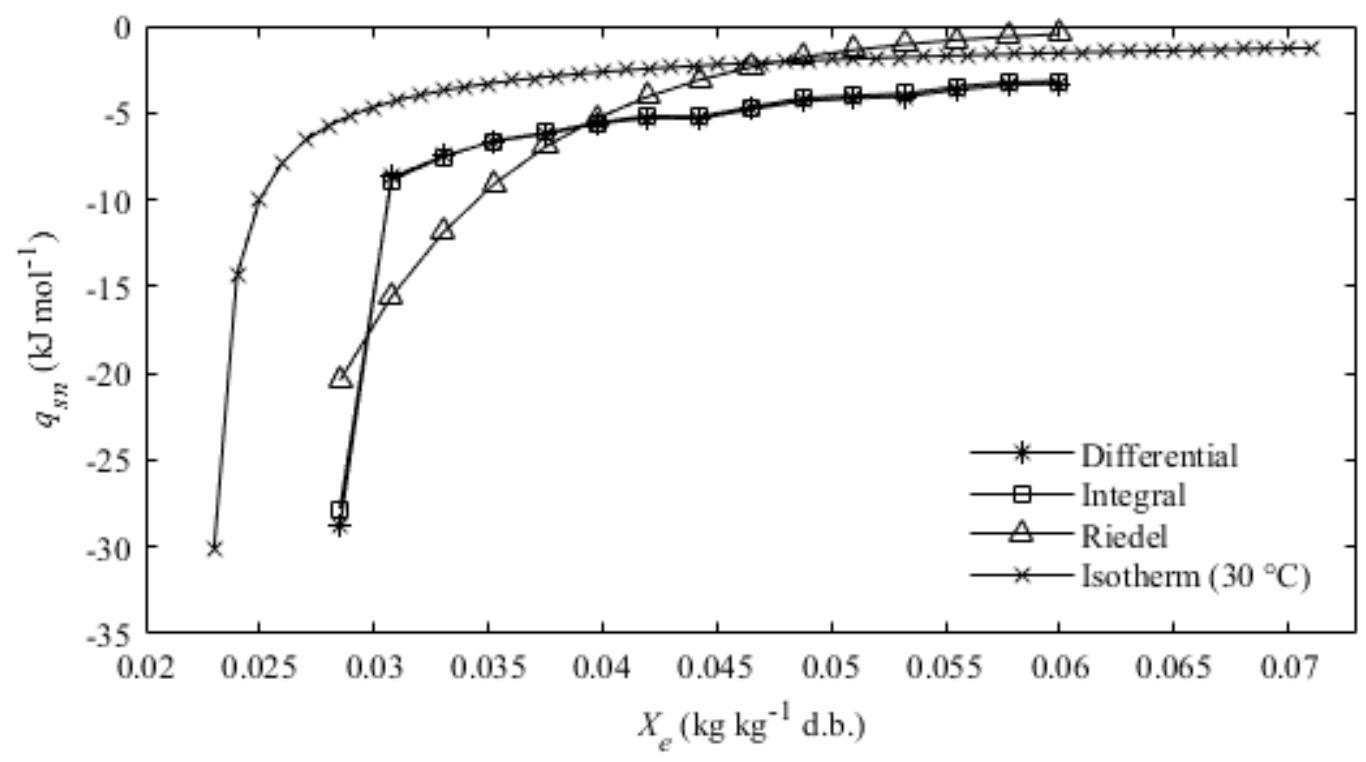

Fig 2. Variation of net isosteric heat of sorptiom diferecnial and integrated in roasted coffee beans

\section{Conclusions}

The equilibrium moisture content increases when temperature increases at constant water activity. The Weibull model was considered the best equation for describing sorption isotherms of roasted coffee beans. The isotherms behaved in a way typical of food rich in soluble components. The net isosteric heat of sorption increases with increments of equilibrium moisture content, indicating a strong bond energy. The trends of the sorption isotherms were similar to those reported for roasted coffee beans of others cultivars.

\section{References}

[1] Aguirre-Laredo, R.Y.; Rodriguez-Hernandez, A.I.; Velazquez, G., 2016. Modelling the effect of temperature on the water sorption isotherms of chitosan films. Food Science and Technology. DOI: http://dx.doi.org/10.1590/1678-457X.09416

[2] Bastıoğlu, A. Z., Koç, M., Ertekin, F. G., 2017. Moisture sorption isotherm of microencapsulated extra virgin olive oil by spray drying. Food Measure DOI 10.1007/s11694-017-9507-4

[3] Bon, J., Vaquiro, H. A., Mulet, A., 2012. Modeling sorption isotherms and isosteric heat of sorption of mango pulp cv. Tommy Atkins. Biotecnología en el Sector Agropecuario y Agroindustrial. Vol 10 No. 2 (34 - 43).

[4] Brunauer, S., Deming, S. L., Deming, E. W., Teller, E., 1940. On a Theory of the van der Waals Adsorption of Gases. J. Am. Chem. Soc. DOI: 10.1021/ja01864a025 
[5] Caballero-Cerón, C., Serment-Moreno, V., Velazquez, G., Torres, J. A. Welti-Chanes, J., 2017. Hygroscopic properties and glass transition of dehydrated mango, apple and banana. J Food Sci Technol https://doi.org/10.1007/s13197-017-2963-3

[6] Ferreira de souza, J. S.; Vaquiro, H. A; Villa-Velez, A. H.; Polachini, C. T.; Telis-Romero, J.; International Journal of Food Engineering. 2014. DOI: 10.1515/ijfe-2014-0138

[7] García-Pérez, J. V., Cárcel, J. A., Clemente, G., Mulet, A., 2008. Water sorption isotherms for lemon peel at different temperatures and isosteric heats. Swiss Society of Food Science and Technology. Published by Elsevier Ltd. All rights reserved. doi:10.1016/j.lwt.2007.02.010

[8] Iaccheri, E., Laghi, L., Cevoli, C., Berardinelli, A., Ragni, L., Romani, S., Rocculi, P., Different analytical approaches for the study of water features in green and roasted coffee beans. Journal of Food Engineering. https://doi.org/10.1016/j.jfoodeng.2014.08.016

[9] Khawas, P., Chandra, D. S., 2016. Moisture sorption isotherm of underutilized culinary banana flour and its antioxidant stability during storage. Journal of Food Processing and Preservation ISSN 1745-4549. doi:10.1111/jfpp.13087

[10] Baptestini, M. F., Corrêa, P. C., Horta de Oliveira, Cecon, P. R., Ferreira, S. F., 2017. Kinetic modeling of water sorption by roasted and ground coffee. Acta Scientiarum. DOI: 10.4025/actasciagron.v39i3.32576

[11] Mousa, W., Mohamad, F., Jinap, S. G., Mohd, H., Radu, S., 2012. Sorption isotherms and isosteric heats of sorption of Malaysian paddy. J Food Sci Technol DOI 10.1007/s13197-012-0799-4

[12] SCAA - Specialty Coffee Association of America. 2015. SCAA Protocols cupping specialty coffee.Consultado el 5 de enero de 2018. http://scaa.org/?page=resources\&d=cupping-protocols

[13] Shigehisa, T., Inoue, T., Kumagai, H., 2015. Matematical model of water sorption isotherms of UBC. Fuel Processing Technology. DOI http://dx.doi.org/10.1016/j.fuproc.2014.11.023

[14] Shittu, T. A., Idowu-Adebayo, F., Adedokun, I. I., Alade, O., 2015. Water vapor adsorption characteristics of starch-albumen powder and rheological behavior of its paste. Nigerian Food Journal. DOI: http://dx.doi.org/10.1016/j.nifoj.2015.04.014

[15] Sormoli, M. E., Langrish, T. A.G., 2015. Moisture sorption isotherms and net isosteric heat of sorption for spray-dried pure orange juice poder. LWT - Food Science and Technology. http://dx.doi.org/10.1016/j.lwt.2014.09.064

[16] Staudt, P. B., Kechinski, C. P., Tessaro. I. C., Marczak, L. D. F., Soares, R de P., Cardozo, N. S. M., 2013. A new method for predicting sorption isotherms at different temperatures using the BET model. Journal of Food Engineering. DOI http://dx.doi.org/10.1016/j.jfoodeng.2012.07.016

[17] Uribe, L., Vega-Gálvez, A., Di Scala, K., Oyanadel, R., Torrico, S. J., Miranda, M., 2011. Characteristics of Convective Drying of Pepino Fruit (Solanum muricatum Ait.): Application of Weibull Distribution. Food Bioprocess Technol. DOI 10.1007/s11947-009-0230-y 